\title{
Our experience training a neurocardiologist: a case for an emerging specialty
}

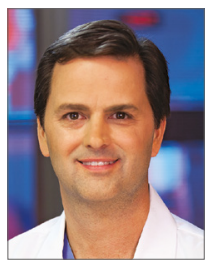

Thomas Haldis*, DO; Michael Manchak, MD; Eugeni Kouznetsov, MD, FRCSC; Tyler Remund, PhD; Alex Drofa, MD, FRCSC

Sanford Health, Fargo, ND, USA

\section{Introduction}

Treatment of acute ischaemic stroke with mechanical thrombectomy is now supported with level 1 evidence ${ }^{1}$. The vast majority of thrombectomies are currently performed by neurointerventionalists. Unfortunately, the current supply of neurointerventionalists is inadequate; while there is only one cerebrovascular neurosurgery programme in our region, there are nine established ST-elevation myocardial infarction (STEMI) programmes. To address this shortcoming, we believe that the established STEMI infrastructure may serve as a bridge.

We propose a model where interventional cardiologists interested in treating acute ischaemic stroke can be trained as "neurocardiologists" in a systematic and controlled fashion. We have adopted a structured approach to stroke neurointervention training that includes teaching clinical assessment skills of the patient in the emergency room, interpretation of imaging and clinical data, decision-making skills as they relate to thrombectomy, as well as performance of thrombectomy itself. The baseline technical requirements include independent performance and review of 100 cerebral angiograms, placement of 25 carotid stents, as well as supervised performance of at least 25 mechanical thrombectomies. Specific training related to obtaining appropriate access, navigating the cerebral circulation, use of stroke-specific devices, and complication avoidance and management is emphasised. Trainees are required to attend stroke codes, spend time with stroke neurology, diagnostic neuroradiology, cerebrovascular neurosurgery, and to see patients postop in the neuro intensive care unit for a period of six months. In accordance with the Standards of Practice in Interventional Neuroradiology, the trainee is constantly mentored and supervised by the staff cerebrovascular neurosurgeons who can manage complications by both endovascular and open surgical means ${ }^{2}$. Once the cerebrovascular neurosurgeon gives approval, the neurocardiologist may independently cover a stroke call. Here we present the early experience of a single independent neurocardiologist immediately following such training.

\section{Methods and results}

Fifteen sequential patients who presented with proximal occlusion of large vessels of the cerebrovascular system were treated by the neurocardiologist, and their de-identified charts were reviewed retrospectively as part of internal quality assurance.

The patients were selected for intra-arterial recanalisation treatment according to our institution's acute stroke protocol for recanalisation strategies. Initially, the patients were assessed for intravenous thrombolysis eligibility using the National Institute of Neurological Disorders and Stroke (NINDS) and the European Cooperative Stroke Study 3 trial criteria. Prior to treatment, the patients were taken for computed tomography angiography (CTA) and hyperacute magnetic resonance imaging (MRI). The decision on treatment was always made in collaboration with the stroke neurologist. Intervention was performed using a stent retriever with aspiration. Successful recanalisation was defined as a Thrombolysis In Cerebral Infarction (TICI) score of 3 or $2 \mathrm{~B}$ in all of the treatable vessels. 
Patients were evaluated with vessel imaging (CTA and MRI). The mean patient age was 73.8 years, and there were eight females. The mean time from symptom onset to arrival was 233 minutes, arrival to groin puncture was 45 minutes, and groin puncture to revascularisation was 23.4 minutes. The patients' NIHSS scores averaged 15.8 on presentation. Vessel occlusions were located in the middle cerebral artery $(76.5 \%)$, posterior cerebral artery (5.9\%), distal internal carotid artery (5.9\%), tandem carotid occlusion $(5.9 \%)$, and basilar artery $(5.9 \%)$. The average number of device passes per vessel was 1.8. Freedom from dissection, embolisation to new territory and intracranial haemorrhage were noted in all 15 patients. Ninety-day survival was noted in 13 of 15 patients $(86.7 \%)$. The NIHSS scores at 24 hours averaged 4.73. After intervention, twelve patients had TICI scores of 3 and three had TICI scores of $2 \mathrm{~B}$ for a recanalisation rate of $100 \%$.

\section{Discussion}

For physicians performing neurovascular interventional procedures, the requirements for achievement of competence to perform cerebrovascular percutaneous interventions can be broken down into three skill sets: cognitive, procedural, and clinical. Individual physician outcomes should conform to both national standards and institutional requirements. According to guidelines published in the American Journal of Neuroradiology ${ }^{3}$, a successful operator should be able to achieve successful recanalisation (modified TICI $2 \mathrm{~B}$ or 3 ) in at least $60 \%$ of cases, to have a symptomatic intracranial haemorrhage rate of less than $10 \%$ and for embolisation to a new territory to occur in fewer than $15 \%$ of cases. Our newly trained neurocardiologist met each of these requirements.

It is important to note that we believe it best for stroke patients to be treated in a dedicated stroke centre. In addition to proper training for neurocardiologists, it is critical that a stroke centre has on-site expertise in vascular neurology and neuro critical care. As such, we feel it is critical that the patients be treated in a centre which has 24-hour access to angiography suites suitably equipped to treat stroke patients and handle the complications.

\section{Limitations}

It is difficult to generalise our single-centre limited experience. Because of this limitation, we believe that a pilot multicentre study involving a larger number of cardiologists may be needed before the training programme can be endorsed by any scientific societies.

\section{Conclusions}

The presented work is evidence that the technical skills necessary to perform coronary interventions are transferable to the cerebral vasculature. For interventional cardiologists who are inexperienced in the treatment of cerebrovascular disease, appropriate preparation and training with a team approach that includes an experienced cerebrovascular neurosurgeon and stroke neurologist is necessary before attempting mechanical thrombectomy. Criticism that the standards are being lowered may be countered by the implementation of ongoing quality assurance programmes.

\section{Impact on daily practice}

This work may improve access to acute ischaemic stroke interventions while maintaining quality.

\section{Conflict of interest statement}

T. Haldis reports receiving personal fees from AstraZeneca outside the submitted work. A. Drofa reports receiving personal fees from Mircrovention and Medtronic outside the submitted work. The other authors have no conflicts of interest to declare.

\section{References}

1. Kallmünzer B, Köhrmann M. [Endovascular thrombectomy for ischemic stroke]. [Article in German]. Med Klin Intensivmed Notfmed. 2017;112:674-678.

2. Jansen O, Szikora I, Causin F, Brückmann H, Lobotesis K. Standards of practice in interventional neuroradiology. Neuroradiology. 2017;59:541-544.

3. Lavine SD, Cockroft K, Hoh B, Bambakidis N, Khalessi AA, Woo H, Riina H, Siddiqui A, Hirsch JA, Chong W, Rice H, Wenderoth J, Mitchell P, Coulthard A, Signh TJ, Phatorous C, Khangure M, Klurfan P, terBrugge K, Iancu D, Gunnarsson T, Jansen O, Muto M, Szikora I, Pierot L, Brouwer P, Gralla J, Renowden S, Andersson T, Fiehler J, Turjman F, White P, Januel AC, Spelle L, Kulcsar Z, Chapot R, Spelle L, Biondi A, Dima S, Taschner C, Szajner M, Krajina A, Sakai N, Matsumaru Y, Yoshimura S, Ezura M, Fujinaka T, Iihara K, Ishii A, Higashi T, Hirohata M, Hyodo A, Ito Y, Kawanishi M, Kiyosue H, Kobayashi E, Kobayashi S, Kuwayama N, Matsumoto Y, Miyachi S, Murayama Y, Nagata I, Nakahara I, Nemoto S, Niimi Y, Oishi H, Satomi J, Satow T, Sugiu K, Tanaka M, Terada T, Yamagami H, Diaz O, Lylyk P, Jayaraman MV, Patsalides A, Gandhi CD, Lee SK, Abruzzo T, Albani B, Ansari SA, Arthur AS, Baxter BW, Bulsara KR, Chen M, Delgado Almandoz JE, Fraser JF, Heck DV, Hetts SW, Hussain MS, Klucznik RP, Leslie-Mawzi TM, Mack WJ, McTaggart RA, Meyers PM, Mocco J, Prestigiacomo CJ, Pride GL, Rasmussen PA, Starke RM, Sunenshine PJ, Tarr RW, Frei DF, Ribo M, Nogueira RG, Zaidat OO, Jovin T, Linfante I, Yavagal D, Liebeskind D, Novakovic R, Pongpech S, Rodesch G, Soderman M, terBrugge K, Taylor A, Krings T, Orbach D, Biondi A, Picard L, Suh DC, Tanaka M, Zhang HQ. Training Guidelines for Endovascular Ischemic Stroke Intervention: An International Multi-Society Consensus Document. AJNR Am J Neuroradiol. 2016;37:E31-4. 